\title{
EDITORIAL
}

\section{Potential causes of increased long-term mortality after pneumonia}

\author{
E.M. Mortensen
}

$\mathbf{P}$ neumonia, along with influenza, is currently the eighth leading overall cause of death in the USA, and is the leading cause of infectious death [1]. However, this only considers the immediate impact of an episode of pneumonia on mortality. Almost all research on pneumonia has focused on mortality in the first 30-90 days after presentation [2]. However, there is growing interest in the effects of pneumonia after this immediate period. Sir William Osler famously remarked in his Principals and Practices of Medicine, "Pneumonia may well be called the friend of the aged. Taken off by it in an acute, short, not often painful illness, the old male escapes those cold gradations of decay so distressing to himself and to his friends" [3]. Although this may have been the case prior to the advent of antimicrobial therapy in the 1940s, recent studies have cast this assertion into serious doubt.

In 1998, BRANCATI et al. [4] published a study examining 141 patients hospitalised for pneumonia. They found that $16 \%$ died during the initial hospitalisation and that an additional $32 \%$ of the cohort, who survived until discharge, died within the next 24 months. Although this increased mortality was associated with severe comorbid conditions, there was no significant relationship to increasing age. In analyses performed as part of the Pneumonia Patient Outcomes Research Trial (PORT) cohort study, MORTENSEN et al. [5] found that of 1,555 patients initially enrolled, $8.7 \%$ died within the first 90 days after hospital admission and that an additional 19.2\% died within 2 yrs of hospitalisation. As compared with average life expectancy, there was significantly lower survival for patients with pneumonia across all age groups, not only for the elderly. Another study by KAPLAN et al. [6] of 158,960 Medicare patients with community-acquired pneumonia who were matched to 794,333 patients hospitalised for other conditions demonstrated a 1-yr mortality of $40.9 \%$ for the pneumonia group versus $24.9 \%$ for the controls. Several other studies support the concept that there is markedly increased mortality for up to several years afterwards for those that initially survive an episode of pneumonia [7-12].

Although studies have clearly demonstrated that there is increased long-term mortality after pneumonia, it is unclear

VERDICT Research Program, South Texas Veterans Health Care System, Dept of Medicine, University of Texas Health Center at San Antonio, San Antonio, TX, USA.

CORRESPONDENCE: E.M. Mortensen, VERDICT Research Program (11C6), 7400 Merton Minter Boulevard, San Antonio, TX, 78229, USA. E-mail: mortensene@uthscsa.edu what the potential reasons are and whether they are modifiable. YENDE et al. [8] found that long-term mortality was independent of comorbid conditions that pre-dated the episode of pneumonia. However, other studies have shown that an increasing number of comorbid conditions are associated with increased long-term mortality [4, 5, 7]. In addition, studies have suggested an increased risk of cardiovascular disease during and after serious infections, such as pneumonia, and it is suggested that cardiovascular events may play an important role in long-term outcomes [13]. In addition, a recent study demonstrated that $\leqslant 10 \%$ of patients hospitalised with pneumonia are diagnosed with either a primary lung cancer or pulmonary metastasis within several years of admission [14]. Therefore, it is likely that other medical conditions and complications are responsible for at least part of this increased mortality.

In this issue of the European Respiratory Journal, GUERTLER et al. [15] examined the prognostic performance of the Pneumonia Severity Index [16] and other bio- and inflammatory markers on long-term outcomes after pneumonia. They examined subjects with community-acquired pneumonia who were enrolled as part of the ProHOSP trial [17], a multicentre, randomised controlled trial that tested whether a procalcitonin-guided algorithm could reduce antibiotic exposure without increasing adverse outcomes. Due to the design of the primary trial, they excluded patients who could not give consent, those with immunosuppression, "imminent death" or hospital-acquired infections, and those who died during the initial hospitalisation. Subjects were followed up for 18 months after joining the study. Of the initial 925 subjects with pneumonia enrolled in the parent trial, $5.2 \%(n=48)$ died during the initial hospitalisation and an additional $16.4 \%(n=152)$ died within 18 months. Similar to prior studies, they found in the multivariable models that male sex and pre-existing comorbid conditions, such as chronic obstructive pulmonary disease (COPD) and cancer, were associated with increased long-term mortality. Interestingly, they also found that higher peak levels of pro-adrenomedullin were associated with higher long-term mortality, and that history of chills, higher body temperature and higher C-reactive protein levels were associated with lower long-term mortality.

These findings are somewhat counter-intuitive, as studies have demonstrated that a high inflammatory response is associated with worse short-term outcomes after pneumonia [9, 18-20]. However, this study's findings, which were similar to those from the Pneumonia PORT cohort study [5], suggest that there 
are a number of patients with pneumonia who, although able to survive the initial episode of pneumonia, are not able to mount a normal immune response. This inability to mount a sufficient response may predispose these patients to subsequent mortality and morbidity due to other infectious diseases.

It is clear that, contrary to traditional beliefs, pneumonia is only an "acute, short, not often painful illness" [3], but a condition that impacts on patient's morbidity and mortality for up to several years after a single episode. This study illustrates that several significant medical conditions, such as COPD, cardiac disease and malignancy, are some of the reasons behind this increased mortality. In addition, it appears that both elevated and suppressed inflammatory response may also contribute to this increased long-term mortality. Clearly, the contribution of pneumonia to mortality is understated. Clinicians should monitor patients who survive an episode of pneumonia closely for malignancies, worsening respiratory function, cardiac conditions and additional infections. Additional research is urgently needed to further examine the contributors to this long-term mortality and to identify methods to improve longterm survival for patients with pneumonia.

\section{SUPPORT STATEMENT}

This material is the result of work supported with resources and facilities of the South Texas Veterans Health Care System (San Antonio, TX, USA). The views expressed in this article are those of the author and do not necessarily represent the views of the Dept of Veterans Affairs.

\section{STATEMENT OF INTEREST}

None declared.

\section{REFERENCES}

1 Kung HC, Hoyert DL, Xu QJ, et al. Deaths: final data for 2005. Natl Vital Stat Rep 2008; 56: 1-124.

2 Mortensen EM, Coley CM, Singer DE, et al. Causes of death for patients with community-acquired pneumonia: results from the Pneumonia Patient Outcomes Research Team cohort study. Arch Intern Med 2002; 162: 1059-1064.

3 Osler W, ed. The Principles and Practice of Medicine. New York, D. Appleton and Company, 1898; pp. 109-112.

4 Brancati F, Chow JW, Wagener MM, et al. Is pneumonia really the old man's friend? Two-year prognosis after community-acquired pneumonia. Lancet 1993; 342: 30-33.

5 Mortensen EM, Kapoor WN, Chang CC, et al. Assessment of mortality after long-term follow-up of patients with communityacquired pneumonia. Clin Infect Dis 2003; 37: 1617-1624.
6 Kaplan V, Angus DC, Griffin MF, et al. Hospitalized communityacquired pneumonia in the elderly: age- and sex-related patterns of care and outcome in the United States. Am J Respir Crit Care Med 2002; 165: 766-772.

7 Waterer GW, Kessler LA, Wunderink RG. Medium-term survival after hospitalization with community-acquired pneumonia. Am J Respir Crit Care Med 2004; 169: 910-914.

8 Yende S, Angus DC, Ali IS, et al. Influence of comorbid conditions on long-term mortality after pneumonia in older people. $J \mathrm{Am}$ Geriatr Soc 2007; 55: 518-525.

9 Yende S, D'Angelo G, Kellum JA, et al. Inflammatory markers at hospital discharge predict subsequent mortality after pneumonia and sepsis. Am J Respir Crit Care Med 2008; 177: 1242-1247.

10 Johnstone J, Eurich DT, Majumdar SR, et al. Long-term morbidity and mortality after hospitalization with community-acquired pneumonia: a population-based cohort study. Medicine (Baltimore) 2008; 87: 329-334.

11 Bruns $\mathrm{AH}$, Oosterheert JJ, Cucciolillo MC, et al. Cause-specific long-term mortality rates in patients recovered from communityacquired pneumonia compared with the general Dutch population. Clin Microbiol Infect 2010 [Epub ahed of print DOI: 10.1111/ j.1198-743X.2010.03296.x].

12 Sogaard OS, Lohse N, Gerstoft J, et al. Mortality after hospitalization for pneumonia among individuals with HIV, 1995-2008: a Danish cohort study. PLOS ONE 2009; 4: e7022.

13 Corrales-Medina VF, Madjid M, Musher DM. Role of acute infection in triggering acute coronary syndromes. Lancet Infect Dis 2010; 10: 83-92.

14 Mortensen EM, Copeland LA, Pugh MJ, et al. Diagnosis of pulmonary malignancy after hospitalization for pneumonia. Am J Med 2010; 123: 66-71.

15 Guertler C, Wirz B, Christ-Crain M, et al. Inflammatory responses predict long-term mortality risk in community-acquired pneumonia. Eur Respir J 2011; 37: 1439-1446.

16 Fine MJ, Auble TE, Yealy DM, et al. A prediction rule to identify low-risk patients with community-acquired pneumonia. $N$ Engl J Med 1997; 336: 243-250.

17 Schuetz P, Christ-Crain M, Thomann R, et al. Effect of procalcitoninbased guidelines vs standard guidelines on antibiotic use in lower respiratory tract infections: the ProHOSP randomized controlled trial. JAMA 2009; 302: 1059-1066.

18 Ortqvist A, Hedlund J, Wretlind B, et al. Diagnostic and prognostic value of interleukin-6 and C-reactive protein in communityacquired pneumonia. Scand J Infect Dis 1995; 27: 457-462.

19 Glynn P, Coakley R, Kilgallen I, et al. Circulating interleukin 6 and interleukin 10 in community acquired pneumonia. Thorax 1999; 54: 51-55.

20 Bauer TT, Monton C, Torres A, et al. Comparison of systemic cytokine levels in patients with acute respiratory distress syndrome, severe pneumonia, and controls. Thorax 2000; 55: 46-52. 